\title{
Resources reviews
}

\author{
Edited by Bob Gann
}

\section{HELP - the Health Education Library for People, India's first Consumer Health Education Resource Centre}

\section{Dr Aniruddha Malpani}

Medical Director, Health Education Library for People, Om Chambers, Kemps Corner, Bombay 400 036. India

The Health Education Library for People (HELP) is the first consumer health information centre in India, and according to the Medical Library Association of the USA is already one of the largest in the world. HELP aims to empower people by providing them with the information they need to promote their health, and prevent and treat medical problems in the family in partnership with their doctor.

The Health Education Library for People summarizes its goals as follows:

- to create and provide access to a reliable and up-to-date collection of consumer health materials, so that people can become better informed about their own health. We believe that the best prescription is knowledge

- to encourage a healthy doctor-patient relationship, since the best patient is a wellinformed one

- to provide resources which doctors can adapt to their own practise, to use for educating their patients;

- to be a useful resource for writers and journalists, and thus improve the quality and accuracy of reporting for medical topics in the lay press

- to act as a stimulus for patients with a particular disease to get together and form self-help support groups, to help each other cope with their disease

- to prevent health fraud and quackery by educating the consumer about health and illness

- ultimately, we hope that well informed patients will demand the best treatment available internationally - and that this will act as an incentive for doctors to update their skills, and for hospitals to improve their facilities.

The centre is a registered charitable trust and a non-profit organization, offering the following facilities:

- air conditioned reading rooms, with a seating capacity for 20-25 persons

- an up-to-date collection of over 5000 consumer health books, 10000 pamphlets, and many magazines and newsletters

- audiovisual educational media, including over 100 video tapes. Videos can be viewed in privacy in the library

- computer software, including over $30 \mathrm{CD}$ ROMs on all health and medical topics

- photocopying facilities

- Internet connection providing information on the latest medical research from all over the world. The library catalogue is computerized and is now available on the Internet at http:// www.healthlibrary.com. The website attracts over 50000 visitors every month from all over the world.

Questions are also answered by post or Email. This is an innovative service called MISS-HELP (Medical Information Search Services from HELP) which allows the library to provide medical information to users from all 
over the world. At present, all materials are in English, but there are plans to translate materials into regional languages in the future.

In order to help doctors to "prescribe information' HELP has started a 'Please Prescribe Information Campaign'. Information prescription pads, have been printed and are widely distributed free to doctors on request. It is important that the doctor discusses the results of this information search with the patient, so that the doctor can guide the patient as to which information is relevant to their particular problem. This can help the doctor and patient to become partners in making medical decisions.

Further information about HELP can be obtained from: E-mail: malpani@bigfoot.com; Website: www.healthlibrary.com.

\section{Research and development in the NHS: how can you make a difference?}

\section{Bec Hanley}

Standing Advisory Group on Consumer Involvement in the NHS Research \& Development Programme, PO Box 1629, Hassocks BN6 8EP, UK

Ask anyone working in Research and Development (R \& D) in the National Health Service (NHS) in England for a simple explanation of the system which employs them, and the chances are they will have a struggle. Ask them how consumers can get involved in R \& D which is funded by the NHS, and you are likely to receive many different, and sometimes conflicting answers. The structure of R \& D in the NHS is complex and confusing to those outside it. It appears almost inaccessible, and sometimes irrelevant, to consumers (by consumers we mean users and potential users of NHS services; their carers; organizations representing consumer interests; and members of the public who are the targets of health promotion campaigns).

A new booklet is now being produced which aims to give a clear and accessible explanation of R \& D in the NHS in England. The booklet explains what $\mathrm{R} \& \mathrm{D}$ is, why it is needed and what kind of R \& D is funded by the NHS. It goes on to outline the different ways in which consumers can get actively involved in R \& D. It explains how to find out about what's going on in research, as well as how to get involved in commissioning and undertaking research, and in interpreting and disseminating results. A list of contacts is included to help people obtain further information.

The booklet is being prepared by the Standing Advisory Group on Consumer Involvement in the NHS R \& D Programme. This Group, which is part of the R \& D structure in England, aims to ensure that consumer involvement in $\mathrm{R} \& \mathrm{D}$ in the NHS improves the way research is prioritized, commissioned, undertaken and disseminated. We believe that consumer involvement will result in research which is more relevant and more reliable.

We asked a range of consumers what they wanted to know about R \& D in the NHS. The booklet is based on the questions they asked. We hope it will enable more consumers to become involved in R \& D in the NHS. The booklet will be available early in 1999, and will be free of charge. We also plan to make a summary available in other languages.

\section{Information for Health}

\section{Bob Gann}

Centre for Health Information Quality, Highcroft, Romsey Road, Winchester SO22 5DH, UK

The new NHS information strategy Information for Health was launched by the Secretary of State for Health on 24 September 1998. Information for patients and the public forms a key part of the strategy, which is set in the context of a new Information Age in which members of the public have electronic access to information and services 24 hours a day.

Specific strategic commitments in the strategy include:

- development of a National Electronic Library for Health providing access to high quality, 